\title{
Secular trend of the leading causes of death in China from 2003 to 2013.
}

\author{
Yongcheng Ren ${ }^{1}$, Ming Zhang ${ }^{2}$, Xinping Luo ${ }^{2}$, Jingzhi Zhao ${ }^{3}$, Lei Yin ${ }^{3}$, Chao Pang ${ }^{3}$, Tianping Feng ${ }^{3}$, \\ Shu Wang ${ }^{2}$, Bingyuan Wang ${ }^{1,2}$, Hongyan Zhang ${ }^{1,2}$, Xiangyu Yang ${ }^{1,2}$, Dongsheng $\mathrm{Hu}^{1}$
}

1. Department of Epidemiology and Health Statistics, College of Public Health, Zhengzhou University, Zhengzhou 450001, China

2. Department of Preventive Medicine, Shenzhen University Health Sciences Center, Shenzhen 518060, China

3. Department of Prevention and Health Care, Military Hospital of Henan Province, Zhengzhou 450000, China

\begin{abstract}
Background: To analyze the epidemiological characteristics and secular trends of the leading causes of death in China.

Methods: Data on the leading causes of death was collected from the Statistical Yearbook of China. Data for 11 years, from 2003 to 2013, was analyzed by regression analysis and chi-square test.

Results: The top 3 causes of death from 2009 to 2013 were cancer, cerebrovascular disease, and cardiopathy, with the role of cardiopathy increasing over time $(\mathrm{P}<0.01)$. The proportion of deaths related to cardio-cerebrovascular diseases in urban and rural areas increased to $41.9 \%$ and $44.8 \%$, respectively, in 2013, and was significantly higher than that for cancer, $25.5 \%$ and $22.4 \%$ (both $\mathrm{P}<0.01$ ). Injury and poisoning in urban or rural areas represented the fifth leading cause of death. In 2006, endocrine, nutritional, and metabolic diseases were the sixth main cause of death, with 3.3\% in urban areas. The role of genito-urinary, respiratory, and digestive system diseases in urban areas and genito-urinary system diseases in rural areas decreased during this period (all $\mathrm{P}<0.05)$.

Conclusion: Cancer, cerebrovascular disease, and cardiopathy accounted for more than 67\% of all deaths from 2007 to 2013 in China, and significantly increased in proportion from 2003 to 2013.

Keywords: Causes of death; China; cancer; cardiovascular disease

DOI: https://dx.doi.org/10.4314/ahs.v17i2.29

Cite as: Ren Y, Zhang M, Luo X, Zhao J, Yin L, Pang C, Feng T, Wang S, Wang B, Zhang H, Yang X, Hu D. Secular trend of the leading causes of death in China from 2003 to 2013. Afri Health Sci. 2017;17(2): 532-537. bttps:/ / dx.doi.org/10.4314/abs.v17i2.29
\end{abstract}

\section{Introduction}

Statistical analysis of death data, an important component of medical statistics, can highlight the determinants of diseases, estimate the trends in causes of death in a specified period and provide references for disease prevention and control. In 1987, China's Ministry of Health
Corresponding author:
Dongsheng $\mathrm{Hu}$,
Department of Epidemiology and
Health Statistics,
College of Public Health,
Zhengzhou University,
Zhengzhou 450001, Henan,
People's Republic of China
Tel: 86-755-86671951
Fax: 86-755-86671906
Email: hud@szu.edu.cn

established a vital registration system to record the incidence and causes of death. By 2005, this vital registration system covered 41 urban and 85 rural sites, with populations from 30,000-70,0001. At the same time, the sites of the Chinese vital registration system are increasing, and results of the analyses of the original data from the vital registration system are getting published in China Health Statistics Yearbooks by the Ministry of Health annually. With this nationally representative data extracted from the China Statistical Yearbook databases, we examined the proportion and secular trend of the leading causes of death in China from 2003 to 2013 .

\section{Materials and methods}

Data on the proportion and causes of death was collected from the China Statistical Yearbooks (2004-2014)2, organized and published by the Ministry of Health annually since 2004. Data for 2010 was calculated basing on the 2010 National Population Census, the other data was cal- 
culated basing on annual sample surveys of populations. The sampling survey was based on the general population and excluded the populations of Hong Kong, Macao and Taiwan, with the provincial units as a secondary population, by using multistage stratified and cluster probability proportional sampling methods. Health statistics were provided by the national information center for health and family planning commission. Diseases were classified by using the International Classification of Diseases (ICD-10). The specific ICD-10 code range for each aggregated cause of death followed the description in the Disease Classification and Code (GB/T14396-2001), issued by the Ministry of Health ${ }^{3}$. Data was presented as percentages. The proportion of deaths by year were analyzed by regression analysis. Causes of death were compared by chi-square test. Analysis involved use of SAS 9.10 (SAS Inc., Cary, NC, USA). P<0.05 (two-sided) was considered statistically significant.

\section{Results}

From 2003 to 2013, in urban areas, the top 3 consistent causes of death were cancer, cerebrovascular disease, and cardiopathy. In 2008, cardiopathy replaced cerebrovascular disease as the second main cause of death, at $19.7 \%$, and in 2006, endocrine, nutritional, and metabolic diseases ranked sixth, at 3.3\%, replacing digestive diseases. The proportion of deaths related to cardiopathy and nervous system diseases increased significantly from 2003 to $2013(14.4 \%$ to $21.6 \%$ and $0.9 \%$ to $1.1 \%$, respectively, $\mathrm{P}<0.01)$. Digestive, genito-urinary, and respiratory diseases decreased from 2003 to 2013 (3.7\% to $2.6 \%, 1.3 \%$ to $1.0 \%$, and $14.6 \%$ to $12.4 \%$, respectively $\mathrm{P}<0.01$ ), with no significant change in proportion of deaths caused by cerebrovascular disease and cancer. Deaths from injury and poisoning consistently ranked fifth during the past 11 years. The proportion of perinatal diseases and psychogeny dropped from the top 10 causes of death in 2005 and 2008 , but infectious diseases increased to $10^{\text {th }}$ position in 2008. The proportion of total deaths for the top 10 causes in urban areas increased significantly from 2003 to $2013(89.1 \%$ to $94.6 \%, \mathrm{P}<0.01)$ (Table 1$)$.

Table 1. Proportions of the top 10 causes of death in urban areas in china from 2003 to 2013

\begin{tabular}{|c|c|c|c|c|c|c|c|c|c|c|c|c|}
\hline Death causes & 2003 & 2004 & 2005 & 2006 & 2007 & 2008 & 2009 & 2010 & 2011 & 2012 & 2013 & $P$ value \\
\hline Cancer & 25.47 & 23.92 & 22.94 & 27.25 & 28.53 & 27.12 & 27.01 & 26.33 & 27.79 & 26.81 & 25.47 & $>0.05$ \\
\hline $\begin{array}{l}\text { Cerebrovascular } \\
\text { disease }\end{array}$ & 19.95 & 19.09 & 21.23 & 17.66 & 18.04 & 19.62 & 20.36 & 20.23 & 20.22 & 19.61 & 20.27 & $>0.05$ \\
\hline Cardiopathy & 14.43 & 18.80 & 17.89 & 17.10 & 16.29 & 19.65 & 20.77 & 20.88 & 21.30 & 21.45 & 21.60 & $<0.01$ \\
\hline Respiratory disease & 14.63 & 13.12 & 12.57 & 13.06 & 13.10 & 11.86 & 10.54 & 11.04 & 10.56 & 12.32 & 12.37 & $<0.01$ \\
\hline Injury-poisoning & 6.16 & 5.89 & 8.25 & 6.10 & 6.09 & 5.08 & 5.59 & 6.16 & 5.47 & 5.67 & 6.30 & $>0.05$ \\
\hline $\begin{array}{l}\text { Digestive system } \\
\text { disease }\end{array}$ & 3.66 & 3.24 & 3.30 & 2.94 & 2.83 & 2.86 & 2.67 & 2.74 & 2.64 & 2.48 & 2.55 & $<0.01$ \\
\hline $\begin{array}{l}\text { Endocrine } \\
\text { nutritional and } \\
\text { metabolic disease }\end{array}$ & 2.66 & 2.82 & 2.50 & 3.32 & 3.30 & 3.43 & 3.28 & 2.93 & 3.01 & 2.82 & 2.76 & $>0.05$ \\
\hline $\begin{array}{l}\text { Genitourinary } \\
\text { system disease }\end{array}$ & 1.34 & 1.81 & 1.56 & 1.37 & 1.28 & 1.13 & 1.18 & 1.16 & 1.23 & 1.03 & 1.04 & $<0.01$ \\
\hline $\begin{array}{l}\text { Nerve system } \\
\text { disease }\end{array}$ & 0.91 & 0.86 & 0.84 & 0.93 & 0.95 & 1.03 & 1.11 & 0.94 & 1.06 & 1.12 & 1.11 & $<0.01$ \\
\hline Perinatal diseases & 0.89 & 0.52 & $\mathrm{~N} / \mathrm{A}$ & $\mathrm{N} / \mathrm{A}$ & N/A & $\mathrm{N} / \mathrm{A}$ & $\mathrm{N} / \mathrm{A}$ & $\mathrm{N} / \mathrm{A}$ & $\mathrm{N} / \mathrm{A}$ & N/A & $\mathrm{N} / \mathrm{A}$ & N/A \\
\hline Psychogeny & N/A & N/A & 0.95 & 0.65 & 0.87 & $\mathrm{~N} / \mathrm{A}$ & N/A & $\mathrm{N} / \mathrm{A}$ & N/A & N/A & N/A & N/A \\
\hline $\begin{array}{l}\text { Infectious diseases } \\
\text { (excluding } \\
\text { tuberculosis) }\end{array}$ & N/A & N/A & $\mathrm{N} / \mathrm{A}$ & $\mathrm{N} / \mathrm{A}$ & N/A & 0.77 & 0.71 & 0.72 & 0.51 & 0.68 & 1.12 & N/A \\
\hline All other diseases & 9.91 & 9.93 & 7.97 & 9.62 & 8.72 & 7.45 & 6.78 & 3.79 & 6.21 & 6.01 & 5.41 & $<0.01$ \\
\hline
\end{tabular}


In rural areas after 2009, the top 3 causes of death were cancer, cerebrovascular disease, and cardiopathy. The proportion of deaths due to cardiopathy increased from 2003 to $2013(12.0 \%$ to $21.9 \%, \mathrm{P}<0.01)$, and those due to genitourinary and digestive system diseases decreased from 2003 to 2013 (1.9\% to $1.1 \%$ and $2.8 \%$ to $2.3 \%$, respectively, $\mathrm{P}<0.05)$, with no change in proportion of deaths due to cerebrovascular disease and cancer during this period. Injury and poisoning were consistently the fifth cause of death over the years, but the proportion of deaths was higher in rural than urban areas and showed an upward trend $(\mathrm{P}=0.02)$. The proportion of psychogeny, tuberculosis, and perinatal diseases dropped from the top 10 causes of death in 2008, 2006, and 2005, whereas infectious diseases represented the tenth cause of death after 2007 (Table 2).

Table 2. Proportions of the Top 10 Causes of Death in Rural Areas in China from 2003 to 2013

\begin{tabular}{|c|c|c|c|c|c|c|c|c|c|c|c|c|}
\hline Death causes & 2003 & 2004 & 2005 & 2006 & 2007 & 2008 & 2009 & 2010 & 2011 & 2012 & 2013 & $P$ value \\
\hline Cancer & 25.28 & 23.70 & 20.29 & 25.14 & 24.80 & 25.39 & 24.26 & 23.11 & 23.62 & 22.96 & 22.38 & $>0.05$ \\
\hline Respiratory disease & 18.72 & 13.30 & 23.45 & 16.40 & 17.24 & 16.88 & 14.96 & 14.15 & 13.31 & 15.75 & 11.49 & $>0.05$ \\
\hline Cardiopathy & 12.03 & 12.54 & 11.77 & 13.87 & 14.80 & 14.11 & 17.21 & 17.86 & 19.37 & 18.11 & 21.90 & $<\mathbf{0 . 0 1}$ \\
\hline Digestive system disease & 2.78 & 2.81 & 3.24 & 3.28 & 2.69 & 2.65 & 2.22 & 2.37 & 2.17 & 2.54 & 2.32 & $<\mathbf{0 . 0 5}$ \\
\hline $\begin{array}{l}\text { Endocrine nutritional and } \\
\text { metabolic disease }\end{array}$ & 3.56 & 2.52 & 1.17 & 1.57 & 1.52 & 1.79 & 1.72 & 1.66 & 1.65 & 1.62 & 1.79 & $>0.05$ \\
\hline Genitourinary system disease & 1.89 & 1.61 & 1.32 & 1.28 & 1.22 & 0.92 & 1.10 & 1.01 & 1.02 & 1.00 & 1.06 & $<\mathbf{0 . 0 1}$ \\
\hline Psychogeny & $\mathrm{N} / \mathrm{A}$ & $\mathrm{N} / \mathrm{A}$ & 0.44 & 0.73 & 0.60 & $\mathrm{~N} / \mathrm{A}$ & $\mathrm{N} / \mathrm{A}$ & $\mathrm{N} / \mathrm{A}$ & $\mathrm{N} / \mathrm{A}$ & $\mathrm{N} / \mathrm{A}$ & $\mathrm{N} / \mathrm{A}$ & $\mathrm{N} / \mathrm{A}$ \\
\hline Nerve system disease & $\mathrm{N} / \mathrm{A}$ & $\mathrm{N} / \mathrm{A}$ & $\mathrm{N} / \mathrm{A}$ & 0.80 & 0.77 & 0.71 & 0.77 & $\mathrm{~N} / \mathrm{A}$ & 0.76 & 0.95 & 1.04 & $\mathrm{~N} / \mathrm{A}$ \\
\hline $\begin{array}{l}\text { Infectious diseases (excluding } \\
\text { tuberculosis) }\end{array}$ & $\mathrm{N} / \mathrm{A}$ & $\mathrm{N} / \mathrm{A}$ & $\mathrm{N} / \mathrm{A}$ & N/A & $\mathrm{N} / \mathrm{A}$ & 0.76 & 0.76 & 0.66 & 0.71 & 0.86 & 1.21 & $\mathrm{~N} / \mathrm{A}$ \\
\hline All other diseases & 4.19 & 20.72 & 8.13 & 7.67 & 6.81 & 6.47 & 5.56 & 7.32 & 6.83 & 6.78 & 5.17 & $>0.05$ \\
\hline
\end{tabular}

Note. N/A indicates not among the top 10 causes of death in the corresponding year.

In urban areas, the combined proportion of deaths due to cancer, cardiovascular, and cerebrovascular diseases increased significantly from 2003 to 2013 (59.8\% to 67.3\%,
$\mathrm{P}<0.05$ ), with a peak in 2011 at $69.3 \%$, and the combined proportion of deaths due to cardiovascular and cerebrovascular diseases increased $(34.4 \%$ to $41.9 \%, \mathrm{P}<0.01)$ and was higher than that due to cancer $(\mathrm{P}<0.01)$ (Figure 1). 


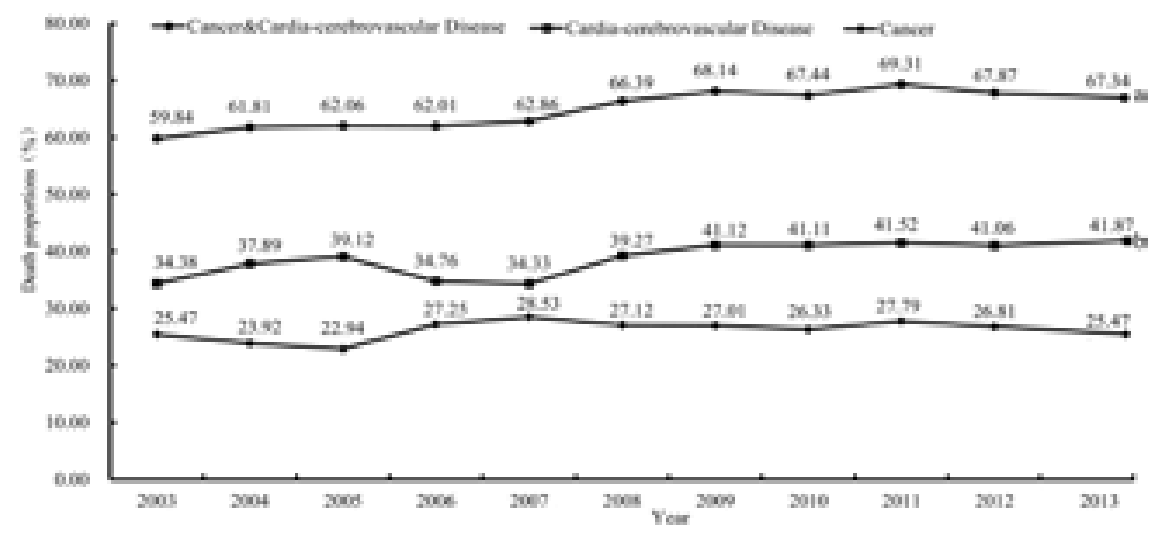

Figure 1. Comparison of trends for cancer and cardiovascular and cerebro vascular diseases as causes of death in urban areas of China from 2003 to 2013.

The trends in rural areas were similar to those in urban areas. The combined proportion of deaths due to cancer, cardiovascular, and cerebrovascular diseases increased from 2003 to $2013(61.1 \%$ to $67.2 \%, \mathrm{P}<0.05)$, and the combined proportion of deaths due to cardiovascular and cerebrovascular diseases increased $(35.8 \%$ to $44.8 \%$, $\mathrm{P}<0.05)$ and was higher than that due to cancer $(\mathrm{P}<0.01)$ (Figure 2). For the top 3 causes of death, only in 2012 and 2013 was the proportion of deaths for cerebrovascular diseases slightly lower in urban than rural areas $(19.6 \%$ vs. $20.6 \%, 20.3 \%$ vs. $22.9 \%$ ).

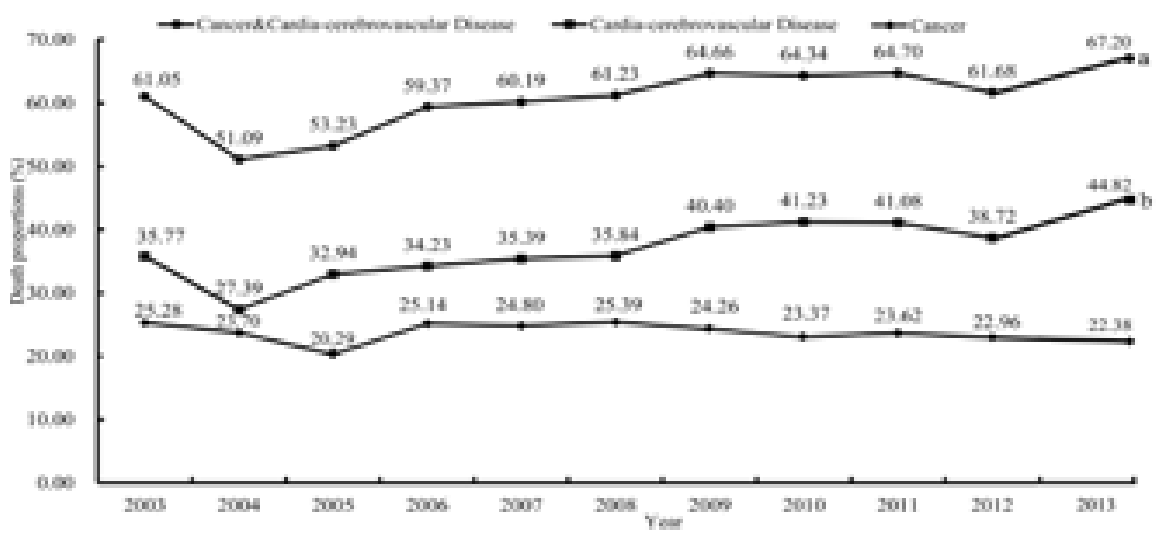

Figure 2. Comparison of trends for cancer and cardiovascular and cerebro vascular diseases as causes of death in rural areas of china from 2003 to 2013. 


\section{Discussion}

With the development of the economy and health services, as well as the increase in life expectancy, the older population is growing ${ }^{4}$. Therefore, the range of chronic diseases will increase, which is a challenge for the limited health resources in China. The prevalence and trends in significant causes of death among Chinese people have been investigated in the 50 years up to 2000 , specifically from 1991 to $2000^{5-7}$. However, in the last decade, the leading causes of death were not clear. In this paper, we report the leading causes of death in China over the past 11 years. We found that non-communicable chronic diseases such as cancer, cardio-cerebrovascular and nutrition-related diseases were among the top causes of death in China during this period.

Over the past 11 years, except for 2005, 2010, and 2013 in rural areas, cancer was consistently the first cause of death among Chinese people. A Chinese population-based retrospective cohort study found that the aging population was the primary cause for the increase in mortality associated with cancer; lung cancer became the top cause of death in China and continues to increase ${ }^{8}$. The proportion of deaths due to cardiopathy-related diseases showed an upward trend and was greater than the proportion attributed to cerebrovascular disease in urban areas after 2008. A recent study found that hypertension was the main risk of cardiopathy ${ }^{9}$. Meanwhile, the $\mathrm{Na}$ tional Health Interview Survey showed that in 2008, the prevalence of circulation system diseases was $85.5 \%$, with hypertension at $54.9 \% 0^{10}$. The combined proportion of deaths due to cardio-cerebrovascular diseases was higher than that for cancer, and the total proportion of deaths due to cancer and cardio-cerebrovascular diseases accounted for more than $60 \%$ of all deaths, thereby representing the main burden of disease in China. Given the aging of the population and the increase in morbidity as a result of hyperlipidemia, hypertension and hyperglycemia, morbidity and mortality due to cancer in China will further increase over the next 10 years, and the proportion of deaths due to cardio-cerebrovascular disease will still be greater than $30 \%$, as published by the World Health Association in $2011^{11}$.

Endocrine, nutritional, and metabolic diseases ranked sixth as a cause of death in urban areas. The increased prevalence of diabetes and obesity was the primary rea- $\operatorname{son}^{12}$. Along with the change in rhythm of life and nature of work, poor diet, sedentary lifestyle and other elements associated with an unhealthy lifestyle, the prevalence of adult obesity increased from $1.3 \%$ to $9.6 \%$ between 1989 and 2009 $9^{13}$; Meanwhile, data from the Chinese Medical Diabetes Association showed that the prevalence of diabetes increased to $9.7 \%$ in 2012, and the total number of cases of diabetics reached around 100 million, surpassing that in India ${ }^{14}$.

Over the past 11 years, injury and poisoning were consistently the fifth leading cause of death in China. However, these are among the main causes of death in young and middle-aged people,especially males, resulting in "early death", and the mortality rate continues to show an upward trend ${ }^{15}$. A study of injuries between 1991 and 2006 in South Korea found a decreased number of traffic accident deaths between 2000 and 2006. However, the suicide rate increased $^{16}$, which suggests that measures to prevent death from injuries have been effective. Focus is needed on reducing the mortality rate from suicide and homicide by paying attention to psychological health and education.

With an improved healthy environment, the mortality rate due to infectious, perinatal, digestive, and genito-urinary system diseases will decline further. However, because of new pathogenic micro-organisms, mutations of microbes, modernized transport and an intense life environment, a pandemic of infectious diseases in China is possible. In 2008, deaths due to infectious diseases increased to tenth position in China. Chinese health authorities still need to be vigilant to contain a possible outbreak of infectious diseases and be prepared for long-term efforts to fight against such a crisis.

Although we extracted the death proportions from national representative data with a large sample size, our study is an exploratory ecological trend study. We did not analyze the determinants of the causes of death.

\section{Conclusion}

The causes of death in China are heavily clustered, with the top 10 causes accounting for more than $94 \%$ of the deaths in 2013. Cancer, cerebrovascular disease and cardiopathy were the top 3 causes,representing more than $67 \%$ of all deaths and have become the main burden of disease. Although the proportion of deaths caused by digestive, genito-urinary, and respiratory system diseases decreased, the causes of cancer, endocrine, nutritional, 
and metabolic diseases are increasing. In addition, the risk of infectious diseases is a concern.

\section{Ethical consideration}

No ethical review committee approval was obtained because the analysis was based on published information.

\section{Acknowledgements}

This study was supported by the National Natural Science Foundation of China (grant no. 81373074), the Natural Science Foundation of Guangdong Province (grant no. S2013010016791), the Science and Technology Development Foundation of Shenzhen (grant nos. JCYJ20120613112221107 and JCYJ20130326110246234) and the Natural Science Foundation of Shenzhen University (grant no. 80100035911). All grants were approved by the Ethics Committee of Shenzhen University School of Medicine (grant nos. 2014-1-1401-001, 2014-2-1310-001, 2014-3-1206-001, 2014-3-1307-002, and 2014-5-1209001 PubMed ).

\section{Conflicts of interest}

None declared.

\section{References}

1. Yang G, Hu J, Rao KQ, Ma J, Rao C, Lopez AD. Mortality registration and surveillance in China: History, current situation and challenges. Popul Health Metr. 2005; 3(1):3.

2. The Ministry of Health. Statistical Yearbook of China 2004-2014. Beijing, China statistical Publishing House, 2004-2013.

3. The Ministry of Health. The national standard of the People's Republic of China-Disease Classification and Code. Beijing, Standards Press of China, 2012.

4. China Aging Problem National Commission. A forecasting research report of the development trend about China's Population Ageing. [Updated 2002 Feb 24; cited 2014 Mar 5]. Available from: http://www.china.com.cn/ chinese/news/1134589.html (in Chinese)

5. The World Bank. China: the longer-term issues and countermeasures in the health pattern transforma- tion. Beijing, China Financial and Economic Publishing House, 1994.

6. Yang GH. Deaths and their risk factors among Chinese population. Beijing, Beijing Union Medical University Press, 2005.

7. Yang GH, Wang Y, Zeng Y, Gao GF, Liang X, Zhou M, et al. Rapid health transition in China, 1990-2010: findings from the Global Burden of Disease Study 2010. Lancet 2013; 381(9882):1987-2015.

8. Zeng HM, Zheng RS, Zhang SW, Zhao P, He J, Chen WQ. Trend analysis of cancer mortality in China between 1989 and 2008. Zhonghua Zhong Liu Za Zhi. 2012; 34(7):525-531.

9. Kelly TN, Gu D, Chen J, Huang JF, Chen JC, Duan $\mathrm{X}$, et al. Hypertension subtype and risk of cardiovascular disease in Chinese adults. Circulation. 2008; 118(15):15581566.

10. Statistical Information Center Of the Ministry of Health. The analysis report of the $4^{\text {th }}$ National Health Services Survey. Beijing, Beijing Union Medical University Press, 2009.

11. WHO. Cardiovascular disease. [Updated 2013 Mar; cited 2014 Mar 14]. Available from: http://www.who.int/ mediacentre/factsheets/fs317/en/index.html

12. Seuring T, Archangelidi O, Suhrcke M. The Economic Costs of Type 2 Diabetes: A Global Systematic Review. Pharmacoeconomics. 2015; 33(8):811-831.

13. Ni GH, Zhang J, Zheng FT. Status and Trends of Chinese Obesity Epidemic. Food and Nutrition in China. 2013; 19(10):70-74.

14. Chinese Medical Association. The situation of the prevention and control of diabetes is grim, and the incidence of diabetes rises rapidly on a global scale. [Updated 2012 Aug 11; cited 2014 Mar 3]. Available from: http:/ / tnb.39.net/a_mtbd/120811/4030986.html (in Chinese)

15. Wang SY, Li YH, Chi GB, Xiao SY, Ozanne-Smith J, Stevenson M, et al. Injury-related fatalities in China: an under-recognised public-health problem. Lancet. 2008; 372(9651):1765-1773.

16. Kim KS, Kim SD, Lee SH. Trend of mortality rate and injury burden of transport accidents, suicides, and falls. J Prev Med Public Health. 2012; 45(1):8-13. 